\title{
Influence of MTHFR gene variations on perceived stress modification: Preliminary results of NURSE study
}

\author{
Maryam Aalaa ${ }^{1}$, Farnaz Najmi Varzaneh ${ }^{1}$, Zhila Maghbooli ${ }^{2}$, Neda Samandari $^{1}$, Ashraf Mostafavi $^{3}$, \\ Sedigheh Salemi ${ }^{3}$, Neda Mehrdad ${ }^{1}$, Mahnaz Sanjari $^{1 *}$
}

\section{Abstract}

Background: High level of perceived stress in nurses is due to a genetic predisposition and environmental stressors. The aim of NURSE (Nursing Unacquainted Related Stress Etiologies) study was to investigate the association of C677T MTHFR gene polymorphism and stress perception among nurses.

Methods: In this comprehensive study, 216 female nurses were recruited. Perceived stress was assessed using the Cohen Perceived Stress Scale (PSS). Genomic DNA was extracted from peripheral blood, and MTHFR genotype was detected by the polymerase chain reaction.

Results: MTHFR C677T genotype analysis revealed that half of the participants had normal C/C genotype, and the remaining half presented higher frequencies of $\mathrm{C} / \mathrm{T}$ genotype $(39.8 \%)$ compared to $\mathrm{T} / \mathrm{T}$ genotype $(10.2 \%)$. The mean $\pm \mathrm{SD}$ stress score in morning shift, night shift, and rotation was $15.39 \pm 4.75,15.92 \pm 4.94$, and $15.83 \pm 5.61$, respectively $(\mathrm{p}=0.7)$. Perceived stress score was more in highly educated group but it was not significant $(\mathrm{p}=0.2)$. Distribution of different MTHFR genotypes in diverse groups revealed that in groups with more stress score, the frequency of heterozygote $(C / T)$ and homozygote $(T / T)$ genotypes increased. Data revealed that in low stress category, $87 \%$ of the participants had a normal genotype. However, in high stress category, $71.3 \%$ of the participants had a normal genotype.

Conclusion: MTHFR genotype, independent of folate availability and probable confounding parameters, might be a potential risk factor of perceived stress among nurses.

Keywords: MTHFR Genotype, Perceived Stress, Nurses

Copyright $\odot$ Iran University of Medical Sciences

Cite this article as:, Aalaa M, Najmi Varzaneh F, Maghbooli Zh, Samandari N, Mostafavi A, Salemi S, 1Neda Mehrdad, Sanjari M. Influence of MTHFR gene variations on perceived stress modification: Preliminary results of NURSE (Nursing Unacquainted Related Stress Etiologies) Study. Med J Islam Repub Iran. 2017 (25 Dec);31:128. https://doi.org/10.14196/mjiri.31.128

\section{Introduction}

Occupational stress is a major hazard of the modern workplace, which can occur by incongruity between job demand and individual's reservoir to carry the burden (1). Job overload, downsizing, extended working hours, argumentative work environments, and shift working are a few of the many causes of stressful working conditions (2). Hospital staff members and health care workers are exposed to high levels of perceived stress (3). Among health

Corresponding author: Dr Mahnaz Sanjari, mahnaz.sanjari@gmail.com

1. Endocrinology and Metabolism Research Center, Endocrinology and Metabolism Clinical Sciences Institute, Tehran University of Medical Sciences, Tehran, Iran.

${ }^{2}$. Osteoporosis Research Center, Endocrinology and Metabolism Clinical Sciences Institute, Tehran University of Medical Sciences, Tehran, Iran.

3. School of Nursing and Midwifery, Iran University of Medical Sciences, Tehran, Iran. care workers, nurses are one of the highly stressed hospital staff members who face significant challenges (4).

High level of perceived stress has been reported in more than $50 \%$ of respondent nurses, which represents a significant health problem for nurses, and in turn to the health organization (5-6).

Workload, overtime, personal responsibility, insufficient pay, and conflict with patients' relatives, physicians

$\uparrow$ What is "already known” in this topic:

High level of perceived stress in nurses is due to a genetic predisposition and environmental stressors. Previous studies investigated the relationship between occupational stress and some biochemical and immunological parameters and the results revealed that hyperhomocysteinaemia (HHcy) has been shown to be an independent risk factor of several primary and secondary disorders of methionine metabolism.

\section{$\rightarrow$ What this article adds:}

The present research provided that the 677TT MTHFR genotype, independent of folate availability and probable confounding parameters, might be a potential risk factor for perceived stress among nurses. 
and colleagues have been shown as the most predominant sources of stress that nurses incur at workplace (7-8). Job stressors can lead to frustration, job dissatisfaction, increasing labor turnover, absenteeism, and ultimately burnout, which appear to be related to emotional and physical well-being and may impact the quality of patients' care (910).

Moreover, occupational stress has been related to a range of adverse physical illnesses such as cardiovascular diseases, gastric ulcer, hypertension, diabetes mellitus, and lipid disorder (11) as well as mental health outcomes including insomnia, depression, and anxiety (12-14). Recently, scientists have been engaged in more basic research to understand how occupational stress contributes to physical illnesses and disease development. Therefore, several scientific studies and surveys have focused on intervening factors and laboratory-based research of underlying biological mechanisms leading to job stress.

In this regard, previous studies investigated the relationship between occupational stress and some biochemical and immunological parameters (15-17). Homocysteine, a non- protein amino acid, is a biochemical marker, which its high level denoted as hyperhomocysteinaemia (HHcy) has been shown to be an independent risk factor of several primary and secondary disorders of methionine metabolism (18). HHCY, observed in roughly $5 \%$ of the general population (19), has been considered as a powerful risk factor for cardiovascular diseases (20), autoimmune disorders (21-22), osteoporosis (23), cancers (24-25), and neuropsychiatric illnesses including dementia (26-27), mood disorders (28), and anger experience (29).

Methylenetetrahydrofolate reductase (MTHFR) is one of the leading regulatory enzymes in homocysteine metabolic pathway, which reduces homocysteine to methionine (30). MTHFR gene, localized to the short (p) arm of chromosome 1 (1p36.3), encodes the MTHFR enzyme (31). A common mutation in MTHFR gene has been associated with increased homocysteine levels and increased risk for several diseases.

Thus far, 3 forms of the MTHFR single nucleotide polymorphisms (SNPs) have been discovered, of which 2 SNPs (C677T and A1298C) affect MTHFR activity (32). The C677T variant of MTHFR results in a missense mutation leading to the substitution of valine for alanine at position 222 of the MTHFR enzyme (33). The homozygous 677TT of MTHFR enzyme with reduced activity altered plasma levels of homocysteine and folate metabolites (34). Because genetic mutation of MTHFR, which impairs its efficiency, is linked to homocysteine level, several studies has been done to find the association of MTHFR polymorphisms with different neurologic and psychiatric disorders (35-37).

To the best of our knowledge, no previous study has examined the relationship between MTHFR genotype polymorphisms and level of appraised stress. Because nursing is one of the occupations with high levels of perceived stress, the correlation between perceived stress and MTHFR genotype polymorphisms has been performed on nursing population to ascertain the MTHFR polymorphism with higher stress level.
The aim and objective of NURSE study was to investigate the association of C677T MTHFR gene polymorphism with stress perception among nurses.

\section{Methods}

\section{Participants}

In a comprehensive study with the aim of investigating health condition in nurses, 216 female nurses were referred by the matron in cooperation with nursing council. Nurses were recruited from 5 different educational hospitals of Tehran University of Medical Sciences (TUMS) in which the first phase of the study was conducted.

The following inclusion criteria were used for entry into the study: female gender, age 22 to 70 years, and a minimum of 6 months job experience. Exclusion criteria were as follow: personal or familial history of major psychiatric disorders, neurological problems, mental retardation, or metabolic diseases. In addition, any participants who had incurable diseases or history of psychotic disorders and a positive history of smoking were excluded from the study.

After semi- structured meetings, which were conducted for verbal explanation of the project to the participants, they were asked to complete a self-administered questionnaire including demographic information, educational level, and types of work shift. Educational level was classified as Bachelor's science degree (Bs), Master's degree (Ms), and Doctorate Degree.

Shift work schedule for nurses in Iran is defined as below: morning shift: 7:30 AM to 2 PM, afternoon shift: 2 PM to 7:30 PM, and evening shift: 7:30 PM to 7:30 AM. In the current study, afternoon shift and evening shift workers were named as night shift workers. Rotation nurses worked a forward rotation schedule: one morning (7:30 AM - 2 PM), one afternoon (2 PM - 7:30 PM), and one evening shift (7:30 PM - 7:30 AM), followed by 2 days off.

\section{Perceived Stress Scale}

Perceived stress was assessed using the Cohen Perceived Stress Scale (PSS). PSS is a widely-used psychological instrument, consisting of 10 items, which measures the perception of stress based on the questions asking about feelings and thoughts over the last month. The items in the PSS are considered as unpredictable, uncontrollable, and overloaded. In each case, respondents were asked how often they felt a certain way. The responses were scored 0 (never), 1 (almost never), 2 (sometimes), 3 (fairly often), or 4 (very often). The total score ranges from 0 to 40 , with higher scores indicating greater degree of perceived stress. Studies of human social stress and health outcomes use the PSS-10, which has good reliability ( $\alpha$ ranges from 0.84 to 0.86$)$ (38).

After being informed of the procedures, all participants who signed the informed consent were enrolled in this study. Study protocols were approved by the Ethics Committees of the Hospital District of TUMS, Matron Council, and Nursing Directory.

\section{Genotyping of the MTHFR Gene Variant}

Four milliliters of blood was collected in tubes contain- 
ing EDTA. The peripheral blood mononuclear cells (PBMCs) were separated from the whole blood through density gradient centrifugation using Ficoll. Genomic DNA was extracted from PBMCs by validated procedures. The detection of MTHFR C677T polymorphism in Exon 4 of MTHFR gene was performed by polymerase chain reaction-restriction fragment length polymorphism (PCR-RFLP) analysis using HINFI digestion, as previously described by Frosst et al. (33). The PCR forward and reverse primers were 5'-AGG ACG GTG CGG TGA GAG TG -3' and 5'-CAAAGG CCA CCC CGA AGC -3', respectively. Existence of the $\mathrm{C} 677 \mathrm{~T}$ mutation in the $\mathrm{PCR}$ product introduced a new HINFI restriction site, which resulted in the digestion of the 246-bp amplicon into 175 and 71-bp fragments. Digested DNA fragments were then separated on a $2 \%$ agarose gel. The validity of the PCRRFLP MTHFR genotype was confirmed by sequencing $15 \%$ of the total PCR products.

\section{Statistical Analysis}

Data were analyzed using SPSS 19 to obtain Mean \pm SD values; Student's t test, analysis of variance, and chisquare tests were used as appropriate. Student's t test and analysis of variance were used to determine differences in means, and chi-square test was used to assess intergroup significance. Effect sizes were expressed as odds ratios with $95 \%$ confidence intervals. The level of significance was set at $\mathrm{p}<0.05$.

\section{Results}

A total of 216 participants were recruited for this study. The demographic characteristics of the participants are demonstrated in Table 1. Based on marriage status, the participants were categorized into 3 groups as single $(30.1 \% ; n=65)$, married $(69.4 \% ; n=150)$, and others $(0.5 \% ; n=1)$. Based on educational level, participants were classified as having a BS degree $(94.5 \% ; n=204)$, MS $(2.3 \% ; n=5)$, and a doctorate degree $(3.2 \% ; n=7)$. Shift works were scheduled as morning shifts $(39.8 \%$; $\mathrm{n}=86)$, night shifts $(24.5 \% ; \mathrm{n}=53)$, and rotation shifts $(35.6 \% ; \mathrm{n}=77)$.

MTHFR C677T genotype analysis revealed that half of the participants had normal $\mathrm{C} / \mathrm{C}$ genotype, and the remaining half presented higher frequencies of the $\mathrm{C} / \mathrm{T}$ genotype $(39.8 \% ; \mathrm{n}=86)$ compared to $\mathrm{T} / \mathrm{T}$ genotype $(10.2 \% ; \mathrm{n}=22)$.

As diversity in working shifts seemed a confounding factor on stress score, the score was analyzed in different shift groups. The mean \pm SD stress score in the morning, night, and rotation shifts was $15.39 \pm 4.75,15.92 \pm 4.94$, and $15.83 \pm 5.61$, respectively. The difference in stress score was not significant among the 3 groups $(p=0.7)$.

Marital status was considered as another confounding factor. In this aspect, stress score was measured in 2 different groups of the married and the single. Mean \pm SD stress score was $15.59 \pm 5.02$ in the married group and $15.90 \pm 5.34$ in the single. There was no significant difference between the 2 groups $(p=0.67)$.

Based on educational level, participants were classified into 2 groups as participants with BS degree and participants holding a degree higher than BS. Mean \pm SD stress score was $15.57 \pm 5.08$ in the group with BS degree and $17.06 \pm 5.32$ in the group with higher than BS degree. Although the perceived stress score was higher in the highly educated group, the difference was not significant between the 2 mentioned groups $(\mathrm{p}=0.2)$.

Table 1 demonstrates the selected characteristics of the participants and stress score with respect to MTHFR genotype polymorphisms. According to Table 1, there was no significant difference in age, height, weight, BMI, marital status, educational level, and shifting work in diverse MTHFR genotype polymorphisms. As there was no difference in the mentioned probable confounding factors among the 3 MTHFR genotypes, the association between stress score and MTHFR polymorphisms was determined. Figure 1 compares stress score with respect to MTHFR genotypes.

Figure 1 shows that stress score in the normal $(\mathrm{C} / \mathrm{C})$ group was lower than that of homozygote $(\mathrm{T} / \mathrm{T})$ and heterozygote $(\mathrm{C} / \mathrm{T})$ groups; however, the difference was not significant $(\mathrm{p}=0.3)$. For further evaluation, stress score was classified into 5 different categories as mentioned in a previous study. Group 1 had the least and Group 5 the highest stress score.

Figure 2 displays the distribution of different MTHFR genotypes in diverse groups categorized based on stress. The figure reveals that in groups with more stress score, the frequency of heterozygote $(\mathrm{C} / \mathrm{T})$ and homozygote (T/T) genotypes increased. There was no (T/T) homozygote genotype in Group 1 with the least stress score, while more than $60 \%$ of $(\mathrm{T} / \mathrm{T})$ homozygotes were in Groups 4 and 5, with the highest stress score. In the next step, participants were classified into 2 major groups as followed based on their MTHFR genotype: Group 1 included normal (C/C genotype) participants and Group 2 included

Table 1. Characteristic of nurses by genotype for the MTHFR Polymorphism

\begin{tabular}{|c|c|c|c|c|c|}
\hline \multirow[b]{2}{*}{ Variables } & \multirow[b]{2}{*}{$\begin{array}{c}\text { Total } \\
(\mathrm{n}=216)\end{array}$} & \multicolumn{3}{|c|}{ Genotypes } & \multirow[b]{2}{*}{$\mathrm{p}$} \\
\hline & & $\begin{array}{c}\text { Normal }(\mathrm{C} / \mathrm{C}) \\
(\mathrm{n}=108)\end{array}$ & $\begin{array}{c}\text { Heterozygote }(\mathrm{C} / \mathrm{T}) \\
(\mathrm{n}=86)\end{array}$ & $\begin{array}{c}\text { Homozygote }(\mathrm{T} / \mathrm{T}) \\
(\mathrm{n}=22)\end{array}$ & \\
\hline Age (year) & $34.92 \pm 6.35$ & $35.72 \pm 6.86$ & $33.72 \pm 2.84$ & $35.68 \pm 5.07$ & 0.078 \\
\hline Height $(\mathrm{cm})$ & $160.14 \pm 6.51$ & $160.6 \pm 6.61$ & $159.35 \pm 6.5$ & $161 \pm 6.01$ & 0.335 \\
\hline Weight (kg) & $66.37 \pm 11.96$ & $70.57 \pm 56.13$ & $62.33 \pm 9.89$ & $65.36 \pm 7.19$ & 0.364 \\
\hline BMI & $24.99 \pm 3.83$ & $25.29 \pm 4.1$ & $24.99 \pm 3.83$ & $24.57 \pm 3.87$ & 0.423 \\
\hline Married (n)\% & $69.4 \%(150)$ & $73.1 \%(79)$ & $62.8 \%(54)$ & $77.3 \%(17)$ & 0.35 \\
\hline Bs*degree $(n) \%$ & $92.6 \%(200)$ & $92.6 \%(100)$ & $91.9 \%(79)$ & $95.5 \%(21)$ & 0.82 \\
\hline Night Shift (n)\% & $24.5 \%(53)$ & $25.9 \%(28)$ & $23.3 \%(20)$ & $22.7 \%(5)$ & 0.9 \\
\hline
\end{tabular}

Values are expressed as mean $\pm \mathrm{SD}$

$\mathrm{BMI}=$ Body Mass Index

*Bs=Bachelor's Degree 


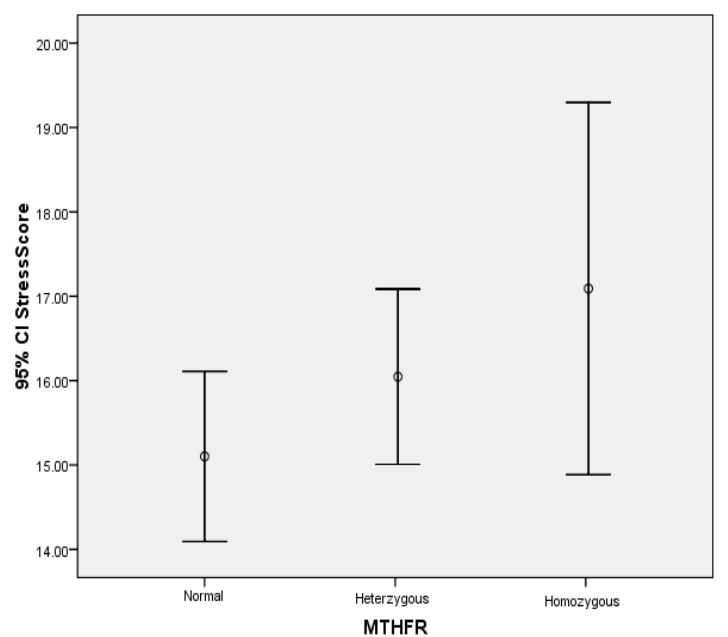

Fig. 1. Stress score in different MTHFR genotypes

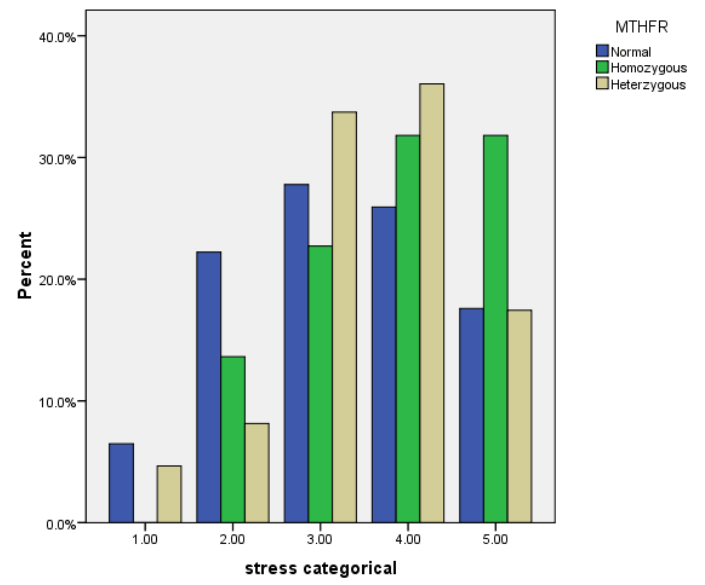

Fig. 2. Distribution of MHFR polymorphisms in different stress score

polymorphic individuals carrying polymorphic allele $(\mathrm{C} / \mathrm{T}$ and $\mathrm{T} / \mathrm{T}$ genotypes).

Furthermore, we classified perceived stress score in 2 categories as low stress defined as stress score $<3$ and high stress defined as stress score $\geq 3$. Data revealed that in the low stress category, $87 \%$ of the participants had a normal genotype. However, in the high stress category, $71.3 \%$ of the participants had a normal genotype. The results also supported a relative risk of 2.21 (95\% CI: 1.18-1.88), which means that the risk of stress in participants carrying the polymorphic allele genotype was more than 2 folds. Thus, work-related confounders such as work shift, marital status, and educational level did not affect the strength of association.

\section{Discussion}

Insight into perceived stress has recently been focused and complemented by growing evidence on its biological mechanism and underlying pathways (39).

A wealth of research indicates that perceived physiological stress may lead to various physical and mental disorders through indirect effects on health behaviors and di- rect effects on neuroendocrine and immune pathways (40). Concern over problems associated with perceived stress and the mechanisms leading to diverse diseases has fostered interest in different involving biochemical and immunological parameters.

In this regard, the effect of perceived stress on some biochemical and immunological factors such as cortisol, inflammatory cytokines, C-reactive protein (CRP) level, and homocysteine were evaluated (15). In the recent years, homocysteine has become a subject of great interest due to its implication as a risk factor for cardiovascular diseases (41), psoriasis (42), renal insufficiency (43), spina bifida (44), multiple sclerosis (45), and cognitive disorders (46).

Although numerous studies have focused on the association of physical disorders with homocysteine level, only very few investigations of psychiatric diseases and homocysteine level exist. In this aspect, association of homocysteine level with increased anger, anxiety, and depression has been reported in clinical studies $(29,47)$, whereas data regarding homocysteine level and behavioral stress are sparse (48).

As it was demonstrated that MTHFR 677CT polymorphisms in homocysteine/methionine pathway result in HHcy, many studies suggest that these variants may play a role in common psychiatric disorders $(36,49-50)$. According to the mentioned issues, the current study examined the role of MTHFR C677T polymorphisms on perceived stress.

The results of the present study revealed that individuals with 677TT genotype, which may lead to HHY, are predisposed to higher stress perception as compared to those with $677 \mathrm{CT}$ and $677 \mathrm{CC}$ genotypes. In addition, the risk of stress perception was approximately 2.2 folds more in participants bearing the TT genotype than those with the 2 other genotypes. Previous studies corroborated the important role of HHcy on perceived stress by expressing HHcy and perceived stress as 2 independent risk factors for eliciting cardiovascular diseases $(48,51)$.

In this aspect, Kang et al. found a higher level of homocysteine in ship yard workers with high level of job strain compared to low level (11.2 Vs10.8), however, the difference was not significant (48). Martin et al. who mentioned long working hours and shift work as job stressors, found higher levels of plasma homocysteine among long-haul bus drivers than the control group $(18.57 \mathrm{Vs} 9.43 \mu \mathrm{M})$ (17).

Because shift work system leads to fatigue by disrupting the circadian rhythms, sleep problems and anxiety, shift working nurses may be exposed more to higher levels of stress compared to morning shift nurses (52). Thus, different studies have underlined the higher risk of stress exposure, lower work satisfaction, and health problem among night and shift health care workers (53-54).

Association of shift working and major chronic diseases including cancer and cardiovascular disease (CVD) has been reported by previous studies (55). In the present study, perceived stress was slightly higher in night shifts (15.92 \pm 4.94$)$ and rotation shifts $(15.83 \pm 5.61)$ compared to morning shifts $(15.39 \pm 4.75)$; however, the difference was 
not significant.

Therefore, it could be concluded that C677T MTHFR polymorphisms correlate with perceived stress, regardless of the effect of shift work. In addition to shift work, we examined other possible confounding or mediating factors such as educational level and marital status in the analyses.

In the present study, high level of education had a positive impact on more perception of stress, but the correlation was not statistically significant. The result of the current study was compatible with that of the Lee et al. study, which showed higher levels of perceived stress in nurses with higher levels of education (5). On the contrary, Feizi et al., who analyzed the impact of some predictive variables on levels of perceived stress among approximately 4500 Iranian people, found that higher levels of education were negatively associated with perceived stress, measured by Goldberg General Health Questionnaire (GHQ) questionnaire (56).

The discrepancy between studies on educational level and stress perception could be explained by the fact that on the one hand, higher levels of education could lead to higher income and socioeconomic status, which may lead to lower perception of stress (57); and on the other hand, high educational achievement follows an occupation with more responsibilities and job strain, which may lead to a higher level of stress perception.

Likewise, regarding the association between marital status and perceived stress, the current study revealed a slightly higher level of perceived stress in single respondent nurses compared to the married, which was in contrast to Feizi et al. results (56). The discrepancy between the 2 studies may be due to different physiological instrument measuring the perceived stress.

Therefore, the results of the current study revealed that significant interrelationships occurred among perceived stress and C677T polymorphisms even when the mentioned confounding factors were adjusted for in a multiple regression analysis.

\section{Conclusion}

In conclusion, our data suggest that the 677TT MTHFR genotype, independent of folate availability and probable confounding parameters, might be a potential risk factor for perceived stress among nurses. As a result, special attention should be devoted to stressful occupations such as nursing with particularly homozygote $\mathrm{T} / \mathrm{T}$ and heterozygote C/T MTHFR genotype. Therefore, the results of the present study can be interpreted as a useful assessment to identify the individuals with higher risk of stress perception.

To our knowledge, no previous studies were published demonstrating the association between MTHFR genotype and stress perception. The results of the study has highlighted the importance of genetic influence on stress perception, however, it deserves further investigation in the aspect of MTHFR enzyme, folate level, and B12 in perceived stress.

\section{Acknowledgments}

This study was fully supported by Endocrinology and Metabolism Research Institute of Tehran University of Medical Sciences. No conflict of interest has been declared by the authors. This research received no specific grant from any funding agency in the public, commercial, or not-for-profit sectors.

Conflict of Interests

The authors declare that they have no competing interests.

\section{References}

1. Lederer N. Healthy Work: Stress, Productivity, and the Reconstruction of Working Life (Book). Library Journal. [Book Review]. 1990;115(1):126-.

2. Harada H, Suwazono Y, Sakata K, Okubo Y, Oishi M, Uetani M, et al. Three-shift system increases job-related stress in Japanese workers. J Occup Health. 2005 Sep;47(5):397-404.

3. Wolfgang AP, Perri M, 3rd, Wolfgang CF. Job-related stress experienced by hospital pharmacists and nurses. Am J Hosp Pharm. 1988 Jun;45(6):1342-5.

4. Wu H, Chi TS, Chen L, Wang L, Jin YP. Occupational stress among hospital nurses: cross-sectional survey. J Adv Nurs. 2010 Mar;66(3):627-34.

5. Lee JK. Job stress, coping and health perceptions of Hong Kong primary care nurses. Int J Nurs Pract. 2003 Apr;9(2):86-91.

6. Laranjeira CA. The effects of perceived stress and ways of coping in a sample of Portuguese health workers. J Clin Nurs. 2012 Jun;21(1112): $1755-62$.

7. Kane PP. Stress causing psychosomatic illness among nurses. Indian J Occup Environ Med. 2009 Apr;13(1):28-32.

8. Xianyu Y, Lambert VA. Investigation of the relationships among workplace stressors, ways of coping, and the mental health of Chinese head nurses. Nurs Health Sci. 2006 Sep;8(3):147-55.

9. Murgia C, Sansoni J. [Stress and nursing : study to evaluation the level of satisfaction in nurses]. Prof Inferm. 2011 Jan-Mar;64(1):3344.

10. Elkins G, Cook T, Dove J, Markova D, Marcus JD, Meyer T, et al. Perceived stress among nursing and administration staff related to accreditation. Clin Nurs Res. 2010 Nov;19(4):376-86.

11. Djindjic N, Jovanovic J, Djindjic B, Jovanovic M, Jovanovic JJ. Associations between the Occupational Stress Index and Hypertension, Type 2 Diabetes Mellitus, and Lipid Disorders in Middle-Aged Men and Women. Ann Occup Hyg. 2012 Nov;56(9):1051-62.

12. Di Donato A, Di Giampaolo L, Reale M, Dadorante V, Alparone F, Stocchi M, et al. Effect of occupational stress and anxiety on natural killer lymphocyte activity of men and women employed in a university. Int J Immunopathol Pharmacol. 2006 Oct-Dec;19(4 Suppl):79-84

13. Gallery ME, Whitley TW, Klonis LK, Anzinger RK, Revicki DA. A study of occupational stress and depression among emergency physicians. Ann Emerg Med. 1992 Jan;21(1):58-64.

14. Utsugi M, Saijo Y, Yoshioka E, Horikawa N, Sato T, Gong Y, et al. Relationships of occupational stress to insomnia and short sleep in Japanese workers. Sleep. 2005 Jun;28(6):728-35.

15. Amati M, Tomasetti M, Mariotti L, Tarquini LM, Ciuccarelli M, Poiani M, et al. [Study of a population exposed to occupational stress: correlation among psychometrics tests and biochemicalimmunological parameters]. G Ital Med Lav Ergon. 2007 JulSep;29(3 Suppl):356-8.

16. Rosmond R, Bjorntorp P. Occupational status, cortisol secretory pattern, and visceral obesity in middle-aged men. Obes Res. 2000 Sep;8(6):445-50.

17. Martins PJ, D'Almeida V, Vergani N, Perez AB, Tufik S. Increased plasma homocysteine levels in shift working bus drivers. Occup Environ Med. 2003 Sep;60(9):662-6.

18. Blom HJ, Smulders Y. Overview of homocysteine and folate metabolism. With special references to cardiovascular disease and neural tube defects. J Inherit Metab Dis. 2011 Feb;34(1):75-81.

19. Brustolin S, Giugliani R, Felix TM. Genetics of homocysteine 
metabolism and associated disorders. Braz J Med Biol Res. 2010 Jan;43(1):1-7.

20. Refsum H, Ueland PM, Nygard O, Vollset SE. Homocysteine and cardiovascular disease. Annu Rev Med. 1998;49:31-62.

21. Roubenoff R, Dellaripa P, Nadeau MR, Abad LW, Muldoon BA, Selhub J, et al. Abnormal homocysteine metabolism in rheumatoid arthritis. Arthritis Rheum. 1997 Apr;40(4):718-22.

22. Singh S, Singh U, Pandey SS. Increased level of serum Homocysteine in vitiligo. J Clin Lab Anal. 2011;25(2):110-2.

23. Gjesdal CG, Vollset SE, Ueland PM, Refsum H, Drevon CA, Gjessing HK, et al. Plasma total homocysteine level and bone mineral density: the Hordaland Homocysteine Study. Arch Intern Med. 2006 Jan 9;166(1):88-94.

24. Weinstein SJ, Ziegler RG, Selhub J, Fears TR, Strickler HD, Brinton LA, et al. Elevated serum homocysteine levels and increased risk of invasive cervical cancer in US women. Cancer Causes Control. 2001 May;12(4):317-24.

25. Lim YJ, Kim JH, Park SK, Son HJ, Kim JJ, Kim YH. Hyperhomocysteinemia is a risk factor for colorectal adenoma in women. J Clin Biochem Nutr. 2012 Sep;51(2):132-5.

26. Alexopoulos P, Topalidis S, Irmisch G, Prehn K, Jung SU, Poppe K, et al. Homocysteine and cognitive function in geriatric depression. Neuropsychobiology. 2010;61(2):97-104.

27. Malaguarnera M, Ferri R, Bella R, Alagona G, Carnemolla A, Pennisi G. Homocysteine, vitamin B12 and folate in vascular dementia and in Alzheimer disease. Clin Chem Lab Med. 2004;42(9): 1032-5

28. Dittmann S, Seemuller F, Schwarz MJ, Kleindienst N, Stampfer R, Zach J, et al. Association of cognitive deficits with elevated homocysteine levels in euthymic bipolar patients and its impact on psychosocial functioning: preliminary results. Bipolar Disord. 2007 Feb-Mar;9(1-2):63-70.

29. Hapuarachchi JR, Chalmers AH, Winefield AH, Blake-Mortimer JS. Changes in clinically relevant metabolites with psychological stress parameters. Behav Med. 2003 Summer;29(2):52-9.

30. Press RD, Beamer N, Evans A, DeLoughery TG, Coull BM. Role of a common mutation in the homocysteine regulatory enzyme methylenetetrahydrofolate reductase in ischemic stroke. Diagn Mol Pathol. 1999 Mar;8(1):54-8.

31. Goyette P, Sumner JS, Milos R, Duncan AM, Rosenblatt DS, Matthews RG, et al. Human methylenetetrahydrofolate reductase: isolation of cDNA, mapping and mutation identification. Nat Genet. 1994 Jun;7(2):195-200

32. Lopez-Lopez E, Martin-Guerrero I, Ballesteros J, Garcia-Orad A. A systematic review and meta-analysis of MTHFR polymorphisms in methotrexate toxicity prediction in pediatric acute lymphoblastic leukemia. The pharmacogenomics journal. 2012 Oct 23.

33. Frosst P, Blom HJ, Milos R, Goyette P, Sheppard CA, Matthews $\mathrm{RG}$, et al. A candidate genetic risk factor for vascular disease: a common mutation in methylenetetrahydrofolate reductase. Nat Genet. 1995 May; 10(1):111-3.

34. Bagley PJ, Selhub J. A common mutation in the methylenetetrahydrofolate reductase gene is associated with an accumulation of formylated tetrahydrofolates in red blood cells Proceedings of the National Academy of Sciences of the United States of America. 1998 Oct 27;95(22):13217-20.

35. Jonsson EG, Larsson K, Vares M, Hansen T, Wang AG, Djurovic S, et al. Two methylenetetrahydrofolate reductase gene (MTHFR) polymorphisms, schizophrenia and bipolar disorder: an association study. Am J Med Genet B Neuropsychiatr Genet. 2008 Sep 5;147B(6):976-82

36. Tan EC, Chong SA, Lim LC, Chan AO, Teo YY, Tan CH, et al. Genetic analysis of the thermolabile methylenetetrahydrofolate reductase variant in schizophrenia and mood disorders. Psychiatr Genet. 2004 Dec;14(4):227-31.

37. Alatab S, Hossein-nezhad A, Mirzaei K, Mokhtari F, Shariati G, Najmafshar A. Inflammatory profile, age of onset, and the MTHFR polymorphism in patients with multiple sclerosis. J Mol Neurosci. 2011 May;44(1):6-11.

38. Cohen S, Kamarck T, Mermelstein R. A global measure of perceived stress. J Health Soc Behav. 1983 Dec;24(4):385-96.

39. Kelly S, Hertzman C, Daniels M. Searching for the biological pathways between stress and health. Annu Rev Public Health. $1997 ; 18: 437-62$

40. Kunz-Ebrecht SR, Kirschbaum C, Steptoe A. Work stress, socioeconomic status and neuroendocrine activation over the working day. Soc Sci Med. 2004 Apr;58(8):1523-30.

41. Ueland PM, Refsum H. Plasma homocysteine, a risk factor for vascular disease: plasma levels in health, disease, and drug therapy. J Lab Clin Med. 1989 Nov;114(5):473-501.

42. McDonald I, Connolly M, Tobin AM. A review of psoriasis, a known risk factor for cardiovascular disease and its impact on folate and homocysteine metabolism. J Nutr Metab. 2012;2012:965385.

43. van Guldener C, Robinson K. Homocysteine and renal disease. Semin Thromb Hemost. 2000;26(3):313-24.

44. Wilson A, Platt R, Wu Q, Leclerc D, Christensen B, Yang H, et al. A common variant in methionine synthase reductase combined with low cobalamin (vitamin B12) increases risk for spina bifida. Mol Genet Metab. 1999 Aug;67(4):317-23.

45. Zoccolella S, Tortorella C, Iaffaldano P, Direnzo V, D'Onghia M, Paolicelli D, et al. Elevated plasma homocysteine levels in patients with multiple sclerosis are associated with male gender. J Neurol. 2012 Oct;259(10):2105-10.

46. Clarke R, Smith AD, Jobst KA, Refsum H, Sutton L, Ueland PM. Folate, vitamin B12, and serum total homocysteine levels in confirmed Alzheimer disease. Arch Neurol. 1998 Nov;55(11):144955.

47. Bjelland I, Tell GS, Vollset SE, Refsum H, Ueland PM. Folate, vitamin B12, homocysteine, and the MTHFR 677C->T polymorphism in anxiety and depression: the Hordaland Homocysteine Study. Arch Gen Psychiatry. 2003 Jun;60(6):618-26.

48. Kang MG, Koh SB, Cha BS, Park JK, Woo JM, Chang SJ. Association between job stress on heart rate variability and metabolic syndrome in shipyard male workers. Yonsei Med J. 2004 Oct 31;45(5):838-46.

49. Gilbody S, Lewis S, Lightfoot T. Methylenetetrahydrofolate reductase (MTHFR) genetic polymorphisms and psychiatric disorders: a HuGE review. Am J Epidemiol. 2007 Jan 1;165(1):1-13.

50. Arzaghi SM, Hossein-Nezhad A, Shariat SV, Ghodsipour A, Shams J, Larijani B. C677T Methylenetetrahydrofolate Reductase (MTHFR) Gene Polymorphism in Schizophrenia and Bipolar Disorder: An Association Study in Iranian Population. Iran J Psychiatry. 2011 Winter;6(1):1-6.

51. Theorell T, Ahlberg-Hulten G, Jodko M, Sigala F, de la Torre B. Influence of job strain and emotion on blood pressure in female hospital personnel during workhours. Scand J Work Environ Health. 1993 Oct;19(5):313-8.

52. Park J, Ha M, Yi Y, Kim Y. Subjective fatigue and stress hormone levels in urine according to duration of shiftwork. J Occup Health. 2006 Nov;48(6):446-50.

53. Nabe-Nielsen $K$, Tuchsen F, Christensen KB, Garde AH, Diderichsen F. Differences between day and nonday workers in exposure to physical and psychosocial work factors in the Danish eldercare sector. Scand J Work Environ Health. 2009 Jan;35(1):4855.

54. Tobia L, Spera G, Cruciani D, Fanelli C, Diana S, Spagnoli F, et al [Occupational risk stress in shift workers]. G Ital Med Lav Ergon. 2007 Jul-Sep;29(3 Suppl):700-1.

55. Wang XS, Armstrong MEG, Cairns BJ, Key TJ, Travis ARC. Shift work and chronic disease: the epidemiological evidence. Occupat Med. 2011;61:78-89.

56. Feizi A, Aliyari R, Roohafza H. Association of perceived stress with stressful life events, lifestyle and sociodemographic factors: a largescale community-based study using logistic quantile regression Comput Math Methods Med. 2012;2012:151865.

57. Yang T, Rockett IR, Lv Q, Cottrell RR. Stress status and related characteristics among urban residents: a six-province capital cities study in China. PLoS One. 2012;7(1):e30521. 